\title{
1-O-acetylbritannilactone combined with gemcitabine elicits growth inhibition and apoptosis in A549 human non-small cell lung cancer cells
}

\author{
FENG WANG $^{1 *}, \mathrm{HONG} \mathrm{LI}^{2 *}$ and JIAN-OU QIAO ${ }^{3}$ \\ ${ }^{1}$ Department of Thoracic Surgery, Shanghai Ninth People's Hospital, Shanghai JiaoTong University School of Medicine; \\ ${ }^{2}$ Department of Emergency, Shanghai Chest Hospital, Shanghai JiaoTong University School of Medicine; \\ ${ }^{3}$ Department of Respiratory Medicine, Shanghai Ninth People's Hospital, Shanghai JiaoTong University School of Medicine, \\ Shanghai 200011, P.R. China
}

Received November 9, 2013; Accepted June 17, 2014

DOI: $10.3892 / \mathrm{mmr} .2015 .4042$

\begin{abstract}
Non-small-cell lung cancer (NSCLC) accounts for $\sim 85 \%$ of all lung cancer cases, with a 5-year survival rate of $<15 \%$. 1-O-acetylbritannilactone (ABL), a natural chemical component obtained from inula britannica, a Chinese traditional medicine, has been demonstrated to have anticancer activity. In the present study, the antiproliferative and proapoptotic abilities of ABL alone or in combination with gemcitabine in a human NSCLC cell line were investigated. A549 cells were treated in vitro with $\mathrm{ABL}$, gemcitabine, and a combination of $\mathrm{ABL}$ and gemcitabine for $72 \mathrm{~h}$. The results demonstrated that ABL and gemcitabine inhibited cell growth and induced apoptosis of A549 cells. These effects were more potent following the combination of $\mathrm{ABL}$ and gemcitabine treatment than either agent alone. Furthermore, the signal transduction analysis revealed nuclear factor (NF) $-\kappa \mathrm{B}$ expression was significantly decreased by $\mathrm{ABL}$ and the combination treatment. The inhibitor nuclear factor $\kappa \mathrm{B} \alpha(\mathrm{I} \kappa \mathrm{B} \alpha)$ and $\mathrm{Bax}$ levels were upregulated whereas Bcl-2 was substantially downregulated following treatment. The present findings suggest that ABL combined with gemcitabine elicits potent apoptosis of lung cancer cells and therefore, ABL has the potential to be developed as a chemotherapeutic agent.
\end{abstract}

\section{Introduction}

Lung cancer is the leading cause of cancer-related mortality worldwide. Non-small-cell lung cancer (NSCLC) accounts for

Correspondence to: Dr Jian-Ou Qiao, Department of Respiratory Medicine, Shanghai Ninth People's Hospital, Shanghai JiaoTong University School of Medicine 639 Zhizaoju Road, Shanghai 200011, P.R. China

E-mail: qjou@163.com; qjianou107@163.com

${ }^{*}$ Contributed equally

Key words: 1-O-acetylbritannilactone, gemcitabine, non-small-cell lung cancer, apoptosis $\sim 85 \%$ all cases of lung cancer $(1,2)$, and commonly develops resistance to chemotherapy and radiotherapy, often presents at stages too late for surgical intervention, resulting in a five-year survival rate of $<15 \%$ (3).

In the past three decades, several chemotherapeutic agents (such as platinum, gemcitabine and pemetrexed) and molecular-targeted agents (such as erlotinib and bevacizumab) have been put into clinical trials. Combination chemotherapy is the preferred standard care of patients with advanced NSCLC, as it can improve patient survival (4).

Gemcitabine (2',2'-difluorodeoxycytidine) is one of the most effective chemotherapeutic agents against NSCLC (5-8). It has been used as a single antitumor agent or in combination with other cytotoxic agents for solid tumor types, including ovarian and pancreatic cancer $(9,10)$.

Inula britannica is a commonly used Chinese traditional herbal medicines and its extracts have been reported to have immunomodulatory $(11,12)$, anti-inflammatory $(13)$ and antitumor activities (14-16). 1-O-acetylbritannilactone (ABL) is an effective chemical component extracted from inula britannica. Previous studies have suggested that ABL has anti-inflammatory (13) and anticancer (17-19) activities, and therefore has the potential to be developed as a chemotherapeutic agent. ABL is able to elicit apoptosis of human breast cancer cells and inhibit the growth of human leukemia cell lines in vitro (17-19). However, the effectiveness of ABL alone or in combination with gemcitabine, one of the first-line chemotherapeutic agents for lung cancer, remains unknown. The present study was conducted to investigate the effect and mechanism of ABL combined with gemcitabine on cell growth and apoptosis in human NSCLC A549 cells in vitro.

\section{Materials and methods}

$A B L$. ABL (purity, $>99 \%$ ) was isolated from Inula britannica- $F$. var chinensis Regel and the structure of ABL was determined spectroscopically, as has previously been reported (20).

Cell culture. The A549 human NSCLC cell line (American Type Culture Collection, Manassas, VA, USA) was cultured in 
RPMI-1640 containing $10 \%$ fetal calf serum (FCS), $100 \mathrm{U} / \mathrm{ml}$ penicillin and $100 \mu \mathrm{g} / \mathrm{ml}$ streptomycin, and maintained in a humidified atmosphere of $95 \%$ air and $5 \% \mathrm{CO}_{2}$ at $37^{\circ} \mathrm{C}$. The cells were passaged to ensure exponential growth.

Cell proliferation assay. The 3-(4,5-dimethylthiazol-2-yl)-2,5diphenyltetrazolium bromide (MTT; Sigma Chemicals Co., St Louis, MO, USA) assays were performed to evaluate cell growth and viability following treatment with $\mathrm{ABL}$ and/or gemcitabine in RPMI-1640 medium containing 10\% FCS. The cells were seeded $\left(1 \times 10^{4}\right.$ cells/well $)$ in 96 -well plates at $37^{\circ} \mathrm{C}$ with $5 \% \mathrm{CO}_{2}$ for $72 \mathrm{~h}$. MTT reagent $(5 \mathrm{mg} / \mathrm{ml})$ was added to each well and the cells were incubated for an additional $4 \mathrm{~h}$. The reaction was terminated with $150 \mu$ l dimethylsulfoxide (Sigma Chemicals Co.,) per well. Absorbance values at $490 \mathrm{~nm}$ were determined by using an ELISA reader (Model 680; Bio-Rad, Hercules, CA, USA).

Analysis of cell apoptosis by flow cytometry. The cells were seeded ( $4 \times 10^{5}$ cells per well) in 6-well plates in RPMI-1640 medium for $24 \mathrm{~h}$. The medium was removed and cells were washed with phosphate-buffered saline (PBS); ABL and/or gemcitabine was then added. Following $72 \mathrm{~h}$, the cells were detached by $0.02 \%$ EDTA and fixed overnight in $70 \%$ ice-cold ethanol at $4^{\circ} \mathrm{C}$. Prior to flow cytometric analysis, the fixed cells were centrifuged at $1,800 \mathrm{x}$ g for $10 \mathrm{~min}$, washed twice with PBS and resuspended in propidium iodide (PI) staining solution containing $5 \mu \mathrm{g} / \mathrm{ml}$ PI and $200 \mu \mathrm{g} / \mathrm{ml}$ RNase A (Sigma Chemicals Co.). Using a FACScan flow cytometer (FCM-500; Beckman Coulter Inc., Los Angeles, CA, USA), cell apoptosis analysis was performed on 10,000 cells for each sample.

Western blot analysis. The cellular lysates were separated by $10 \%$ sodium dodecyl sulfate-polyacrylamide gel electrophoresis and electro-transferred onto nitrocellulose membranes. Following blocking with $5 \%$ non-fat milk in TBST $(20 \mathrm{~mm}$ Tris-buffered saline, $150 \mathrm{~mm} \mathrm{NaCl}, 0.2 \%$ Tween-20, pH 7.6), the membranes were incubated with specific anti-nuclear factor (NF)-кB p65, anti-Bcl-2, anti-Bax, anti-inhibitor nuclear factor $\kappa \mathrm{B} \alpha(\mathrm{I} \kappa \mathrm{B} \alpha$ ) or anti- $\beta$-actin (Santa Cruz Biotechnology, Inc., Santa Cruz, CA, USA) antibodies at room temperature for $2 \mathrm{~h}$, and subsequently with 1:4,000 horseradish peroxidase-conjugated goat anti-mouse secondary antibody (Santa Cruz Biotechnology, Inc.) for $1 \mathrm{~h}$, immunoreactive bands were visualized by enhanced chemiluminescence (Santa Cruz Biotechnology, Inc., Santa Cruz, CA, USA) kit. $\beta$-actin (BD Biosciences, San Diego, CA, USA) was used to normalize the quantity of the protein on the blot.

Statistical analysis. Data are presented as the mean \pm standard deviation. Differences among the groups were identified by analysis of variance for multiple comparisons, followed by Bonferroni post hoc analysis for the least significant difference. $\mathrm{P}<0.05$ was considered to indicate a statistically significant difference.

\section{Results}

Effect of ABL, gemcitabine and their combination on cell growth in A549 cells. To examine the effect of ABL on cell growth, the A549 human non-small-cell lung cancer cell line was treated with increasing concentrations of ABL $(1.25-20 \mu \mathrm{M})$ for $72 \mathrm{~h}$. As demonstrated in Fig. 1A, the cell growth inhibitory effect of ABL was observed in a dose-dependent manner. The effect on proliferation inhibition reached plateau at $10 \mu \mathrm{M}$. The inhibitory effect at $20 \mu \mathrm{M}$, $49.5 \%(\mathrm{P}<0.001)$ was comparable to that at $10 \mu \mathrm{M}$. This result indicated that $\mathrm{ABL}$ is an effective inhibitor of non-small-cell lung cancer cell growth as a single agent. In another experiment, treatment with $\mathrm{ABL}$ was set at $10 \mu \mathrm{M}$ to ensure the maximal inhibitory effect of this compound. In addition, the effect of gemcitabine $(0.001-10 \mu \mathrm{g} / \mathrm{ml})$ on cell growth was examined in vitro and it was identified that gemcitabine inhibited the proliferation of A549 cells with a strong potency (the inhibitory rate was $62.6 \%$ at $10 \mu \mathrm{M}$ of gemcitabine). Subsequently, the A549 cell lines were co-treated with ABL and gemcitabine. The concentrations of ABL and gemcitabine were $10 \mu \mathrm{M}$ and $10 \mu \mathrm{g} / \mathrm{ml}$, respectively, due to the similar inhibitory effect observed at these dosages in the experiment with each individually. The effect of co-treatment with ABL and gemcitabine on cell proliferation was measured by an MTT assay. Following $72 \mathrm{~h}$ of treatment, the combination of the two agents enhanced the efficacy significantly (cell survival rate, $30.2 \%$ ) on the suppression of cell growth compared with the control, ABL alone, or gemcitabine alone (survival rates at 100, 59.1 and 49.7\%, respectively; Fig. 1B; P $<0.001$ ). The above results demonstrate that $\mathrm{ABL}$ inhibited the cell growth in the A549 cell line and this inhibitory effect was further enhanced when used in combination with gemcitabine.

Effect of ABL alone or in combination with gemcitabine, on A549 cell apoptosis in. The inhibitory effect of cell proliferation may be caused by the induction of apoptotic cell death. To elucidate the mechanism underlying this effect, it was investigated whether ABL alone or in combination with gemcitabine induced cell apoptosis and if so, whether the combination leads to an increase in the rate of apoptosis. The A549 cells were treated with ABL $(10 \mu \mathrm{M})$ alone and in combination with gemcitabine $(10 \mu \mathrm{g} / \mathrm{ml})$. Cell apoptosis was examined by PI staining and FACS analysis. As demonstrated in Fig. 2, $<5 \%$ of the cells cultured with RPMI- 1640 medium were apoptotic and following ABL-treatment at a concentration of $10 \mu \mathrm{M}$ for $72 \mathrm{~h}, 30.4 \%$ of cells were apoptotic $(\mathrm{P}<0.05)$, which was similar to that observed following $10 \mu \mathrm{g} / \mathrm{ml}$ gemcitabine-treatment for $72 \mathrm{~h}$-treatment $(31.4 \%$ of apoptotic cells). Compared with the single treatment, the combination of $\mathrm{ABL}$ and gemcitabine increased the percentage of apoptotic cells $(\mathrm{P}<0.01)$. These findings suggest that ABL has the ability to induce cell apoptosis in vitro and this pro-apoptotic effect may also be markedly increased following the addition of gemcitabine.

$A B L$ alone and combined with gemcitabine suppresses $N F-\kappa B$ activation. Next, the present study aimed to investigate the change in the signaling pathway of NF- $\kappa \mathrm{B}$ in lung cancer cells, including nuclear p65 levels and transcription of all NF- $\mathrm{BB}$-regulated genes. It was identified that ABL alone resulted in marginal suppression of NF- $\mathrm{\kappa B}$ expression (NF- $\kappa \mathrm{B}$ p65 protein level) as determined by western blot analysis. When A549 cells were co-cultured with ABL and gemcitabine, 
A
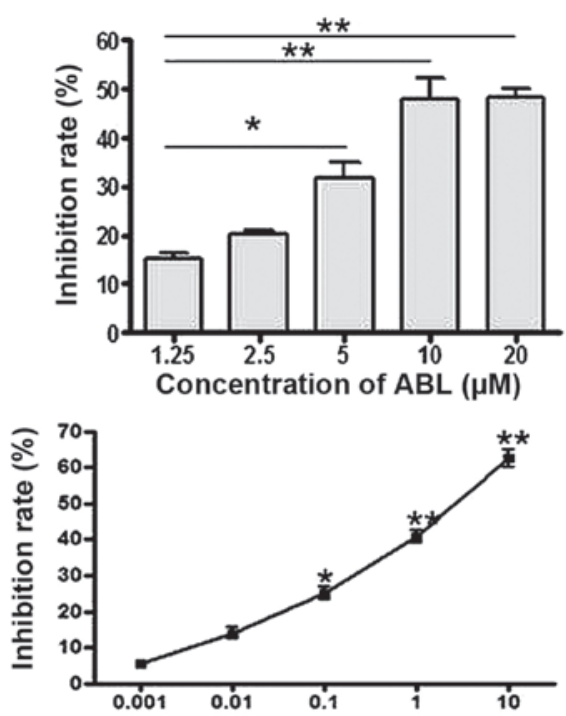

Concentration of gemcitabine $(\mu \mathrm{g} / \mathrm{ml})$

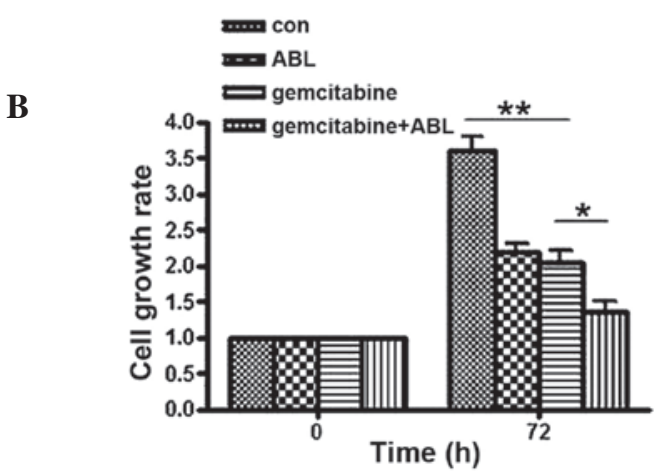

Figure 1. Effect of ABL and gemcitabine alone or in combination on cell growth in A549 cells determined by MTT. (A) Upper panel, ABL treatment; Lower panel, gemcitabine treatment; and (B) the combination treatment The A549 cells $\left(1 \times 10^{4}\right.$ cells/well) were treated with increasing concentrations of ABL $(1.25-20 \mu \mathrm{M})$ or gemcitabine $(0.001-10 \mu \mathrm{g} / \mathrm{ml})$ for $72 \mathrm{~h}$ and measured by MTT. The concentration of ABL $(10 \mu \mathrm{M})$ and gemcitabine $(10 \mu \mathrm{g} / \mathrm{ml})$ used in (B) was based on the results of (A). Data are expressed as the mean \pm standard deviation of three experiments. ${ }^{*} \mathrm{P}<0.05$ and ${ }^{* *} \mathrm{P}<0.001$ ABL, 1-O-acetylbritannilactone; MTT, . 3-(4,5-dimethylthiazol-2-yl)-2,5diphenyltetrazolium bromide.

the $\mathrm{NF}-\kappa \mathrm{B}$ expression was also inhibited and the inhibitory rate was notably more potent compared with treatment with ABL alone (Fig. 3).

Treatment with ABL alone and combined with gemcitabine downregulates Bcl-2, upregulates Bax and prevents degradation of $I \kappa B \alpha$. To investigate the possible mechanism underlying the enhanced cell apoptosis, the expression of I $\kappa \mathrm{B} \alpha$ and $\mathrm{NF}-\kappa \mathrm{B}$ downstream molecules anti-apoptotic Bcl-2 and pro-apoptotic Bax was determined. Western blot analysis (Fig. 4) demonstrated that the expression of Bcl-2 was significantly downregulated in the combination group compared with individual agent treatment group and RPMI-1640 medium control group $(\mathrm{P}<0.01)$, while the expression of Bax markedly increased. The expression of ІкB $\alpha$, which is the inhibitory protein of $\mathrm{NF}-\kappa \mathrm{B}$ activation, was subsequently examined by western blot analysis. Following treatment by $\mathrm{ABL}$ alone and in combination with gemcitabine for $72 \mathrm{~h}$, total $\mathrm{I} \kappa \mathrm{B} \alpha$ expression levels were increased in the two groups.

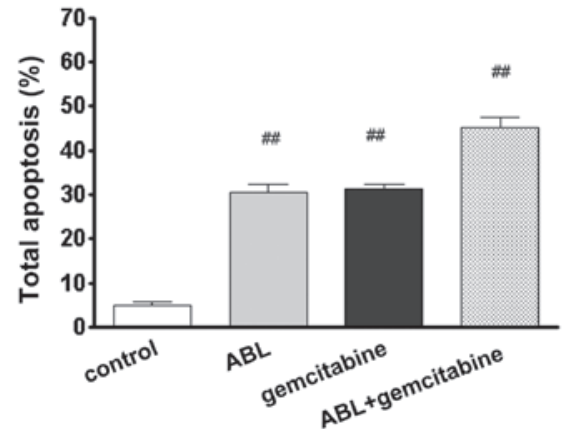

Figure 2. Effect of ABL, gemcitabine and their combination on cell apoptosis in A549 cells determined by FACS. A549 cells $\left(4 \times 10^{5}\right.$ cells/well) were incubated with either ABL $(10 \mu \mathrm{M})$ or gemcitabine $(10 \mu \mathrm{g} / \mathrm{ml})$ or in combination. Following $72 \mathrm{~h}$, cell apoptosis was examined by propidium iodide staining and FACS analysis. The results are representative of three independent experiments. ${ }^{\# /} \mathrm{P}<0.001$ compared with the control. ABL, 1-O-acetylbritannilactone.

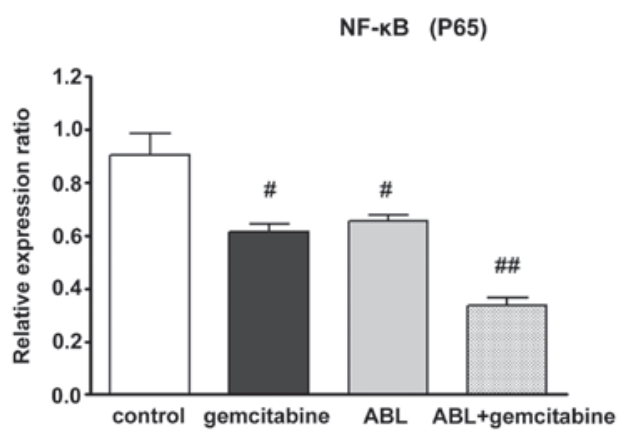

Figure 3. Effects of ABL, gemcitabine and their combination on NF- $\mathrm{B}$ expression. Western blot analysis for NF-KB (p65 sub unit) in nuclear extracts of A549 cells following $72 \mathrm{~h}$ treatment with cell medium, $10 \mu \mathrm{g} / \mathrm{ml}$ of gemicitabine, $10 \mu \mathrm{M}$ of $\mathrm{ABL}$, or their combination. $\beta$-actin protein was used as an internal control. Densitometric measurement for NF- $\kappa \mathrm{B}$ p65 protein levels was normalized to the internal control, and expressed as a relative number. ${ }^{\#} \mathrm{P}<0.01$ and ${ }^{\# \#} \mathrm{P}<0.001$, compared with the control. ABL, 1-O-acetylbritannilactone; NF- $\kappa \mathrm{B}$, nuclear factor- $\kappa \mathrm{B}$.

\section{Discussion}

In the last 25 years, there has been an advance in the understanding of the characteristics of lung cancer. However, progress in the treatment of this disease has been more limited and novel therapies are required to reduce the effects of the increasing incidence of lung cancer. In recent years, the natural chemical compounds from various plants have been investigated as potential antitumor drugs. As traditional Chinese medicine has been used for hundreds of years, there has been increasing interest in identifying novel antitumor agents derived from these herbs. ABL is a natural product extracted from inula britannica, which is a commonly used Chinese traditional medicine. This compound has been reported to exhibit anticancer activities in various cell lines in vitro and is able to induce apoptosis of human breast cancer cells and inhibit the growth of human leukemia cell lines (17-19). However, to the best of our knowledge, the effect of ABL in the A549 human non-small lung cancer cell line has not previously been investigated.

Considering that gemcitabine is one of the first-line chemotherapy drugs for NSCLC, the effects of ABL alone and 
A

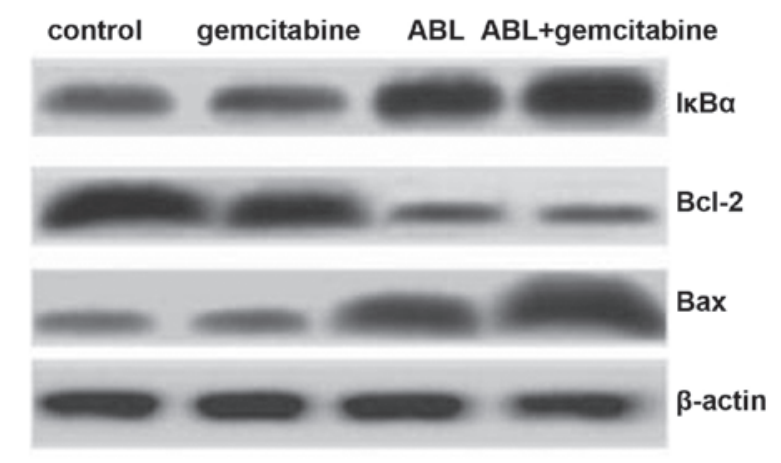

C

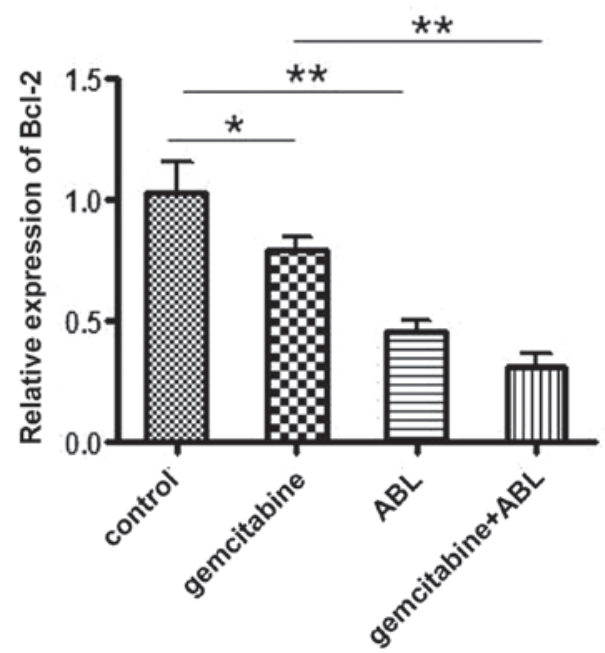

B

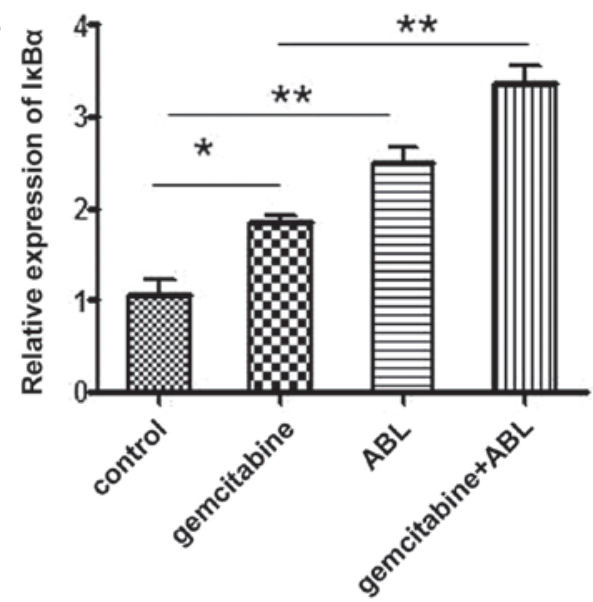

D

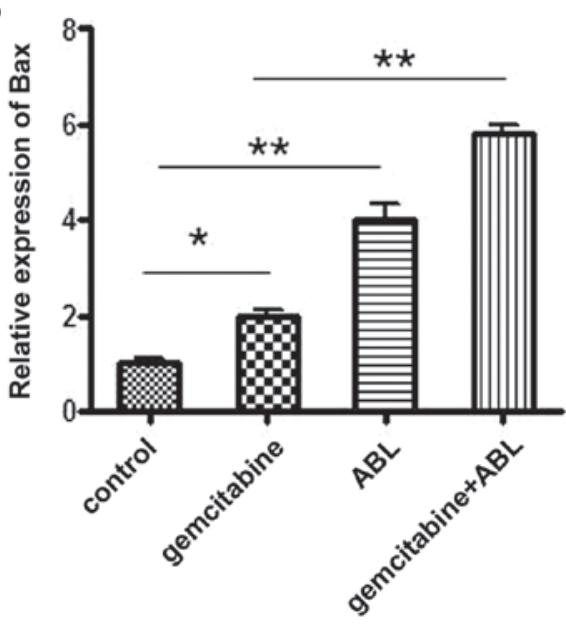

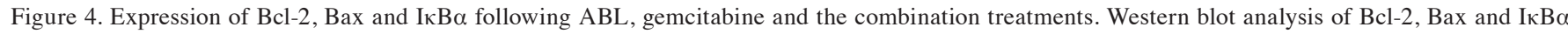
expression in A549 cells treated with cell medium, $10 \mu \mathrm{M} \mathrm{ABL}, 10 \mu \mathrm{g} / \mathrm{ml}$ gemicitabine or their combination for $72 \mathrm{~h}$. (A) The images are representative of three different experiments and show the relative intensities of Bcl-2, Bax and I- $\kappa \mathrm{B} \alpha$ proteins. $\beta$-actin protein was used as an internal control. (B-D) Densitometric measurement for these proteins levels was normalized to the internal control and expressed as a relative number. ${ }^{*} \mathrm{P}<0.05$, ${ }^{* *} \mathrm{P}<0.01$. $\mathrm{ABL}$, 1-O-acetylbritannilactone; $\mathrm{Bcl}-2$, B cell lymphoma gene-2; IкB $\alpha$, inhibitor nuclear factor $\kappa \mathrm{B} \alpha$.

in combination with gemcitabine were investigated in in vitro assays in the present study. The antiproliferative activity was observed in A549 cells in vitro following treatment with ABL alone, gemcitabine alone, and in ABL and gemcitabine in combination. By comparing the results of these three treatment groups, it was observed that there was a synergistic effect on the suppression of proliferation with the combination of ABL and gemcitabine. As it is well established that the inhibitory effect of cell proliferation may be caused by the induction of cell apoptosis, the percentage of apoptotic cells in the treatment groups of ABL alone, gemcitabine alone and in combination was also measured. A similar phenomenon to the cell growth suppression assay was observed; treatment with ABL or gemcitabine alone induced cell apoptosis and the effect was significantly enhanced when the cells were treated by a combination of the two.

The NF- $\mathrm{KB}$ pathway is a key regulator of numerous cellular events, including proliferation, differentiation and apoptosis, and it is also associated with tumor development and progression. It has been reported that NF- $\mathrm{B}$ has bidirectional roles (inhibit or promote) in cell apoptosis and the actual role depends on the stimuli applied and the cell line used in the study. Using western blot analysis, it was identified that the activation of $\mathrm{NF}-\kappa \mathrm{B}$ in
A549 cells was suppressed by treatment with ABL, which may have promoted apoptosis in the tumor cells as was observed in the present study. The effect following the combination of $\mathrm{ABL}$ and gemcitabine was found to inhibit the activation of NF- $\kappa$, which subsequently induced cell apoptosis. Further studies are required to fully understand the underlying apoptotic mechanism of the effects of ABL on A549 cells, including focusing on the apoptosis execution molecules, such as caspase- 3 or caspase- 8 to determine whether the caspase pathway is involved in this apoptotic effect.

Mature NF- $\kappa$ B P65:P50 dimers are trapped in the cytoplasm of unstimulated cells by interaction with the inhibitory protein, termed I $\mathrm{B} \alpha$. The I $\mathrm{KB}$ kinase (IKK) phosphorylates I $\mathrm{I} \mathrm{B} \alpha$ proteins, thereby targeting them for rapid ubiquitin-dependent proteolysis that initiates $\mathrm{NF}-\kappa \mathrm{B}$ activation $(21,22)$. The present study identified that all of the treatments (ABL alone, gemcitabine alone and a combination of the two) were able to upregulate the expression of I $\mathrm{B} \alpha$ in the A549 cells, which maintained the NF- $\mathrm{NB}$ dimers sequestered in an inactive state in the cytoplasm and protected the cell from apoptosis. The activation of $\mathrm{NF}-\kappa \mathrm{B}$ may change the expression of a large number of target genes, including $\mathrm{Bcl}-2$. Bcl-2 family proteins are associated with signal transduction in apoptosis and affect 
the chemosensitivity of tumor cells to anticancer agents (23). It has been revealed that $\mathrm{Bcl}-2$ and $\mathrm{Bcl}-\mathrm{xL}$ (anti-apoptotic protein) protect numerous cell lines from apoptosis induction, while $\mathrm{Bcl}-\mathrm{xS}$ and $\mathrm{Bax}-\alpha$ (pro-apoptotic protein) have the opposite effect (24-26). In the present study, the levels of $\mathrm{NF}-\kappa \mathrm{B}$ downstream molecules Bcl-2 and Bax were measured to examine the possible mechanism underlying the induction of cell apoptosis. The expression of $\mathrm{Bcl}-2$ was significantly downregulated whereas Bax was upregulated in all of the treatment groups compared with the control group, and a synergistic effect was observed following treatment with a combination of the two agents. Several studies have reported that agents that treat lung cancer may induce apoptosis via the Fas/FasL system (27-29). In the present study, the expression of the Fas/FasL system (Fas, soluble and membrane-bound Fas ligand) in A549 cells co-treated with ABL and gemcitabine was also detected. However, there was no significant difference prior to and following the combination treatment. Therefore, it is hypothesized that $\mathrm{ABL}$ alone and in combination with gemcitabine may inhibit the NF- $\mathrm{BB}$ signaling pathway, which is involved in the cell growth and apoptosis of A549 cells. The increased levels of $\mathrm{I} \kappa \mathrm{B} \alpha$ may inhibit NF- $\mathrm{NB}$ expression and activation, and thus induce cell apoptosis. As a result the antiapoptotic Bcl-2 gene was downregulated and the proapoptotic Bax protein was upregulated. Therefore, these results suggest that the mechanism underlying the induction of apoptosis by ABL alone and ABL combined with gemcitabine in A549 cells is by decreasing antiapoptotic gene (Bcl-2) and increasing proapoptotic gene (Bax) expression, respectively.

In conclusion, ABL specifically targets the $N F-\kappa B$ pathway and significantly induces apoptosis in A549 human non-small lung cells in vitro. This effect was significantly enhanced when combined with gemcitabine. The present study merits the further investigation of this compound, as it may represent a novel chemotherapeutic agent in lung cancer treatment if this compound has favorable in vivo pharmacokinetic properties.

\section{Acknowledgements}

This study was supported by the National Natural Science Foundation of China (grant no. 81170028).

\section{References}

1. Jemal A, Siegel R, Ward E, et al: Cancer statistics 2007. CA Cancer J Clin 57: 43-66, 2007.

2. McCracken M, Olsen M, Chen MS Jr, et al: Cancer incidence, mortality, and associated risk factors among Asian Americans of Chinese, Filipino, Vietnamese, Korean, and Japanese ethnicities. CA Cancer J Clin 57: 190-205, 2007.

3. Erridge SC, Moller H, Price A and Brewster D: International comparisons of survival from lung cancer: pitfalls and warnings. Nat Clin Pract Oncol 4: 570-577, 2007.

4. Ramalingam S and Belani C: Systemic chemotherapy for advanced non-small cell lung cancer: recent advances and future directions. Oncologist 13 (Suppl 1): 5-13, 2008.

5. Laskin JJ and Sandler AB: First-line treatment for advanced non-small-cell lung cancer. Oncology (Williston Park) 19: 1671-1676, 2005.

6. Langer F, Helsberg K, Schütte WH and Leschinger MI: Gemcitabine in the first line therapy of advanced and metastatic non-small-cell lung carcinoma (NSCLC): review of the results of phase III studies. Onkologie 28 (Suppl 1): 1-28, 2005.
7. Cucević B, Samarzija M, Baricević D, et al: Gemcitabine in the first and second-line chemotherapy of advanced non-small cell lung cancer. Coll Antropol 29: 583-588, 2005.

8. Natale R: A ten-year review of progress in the treatment of non-small-cell lung cancer with gemcitabine. Lung Cancer 50: S2-S4, 2005.

9. Lund B, Hansen OP, Theilade K, Hansen M and Neijit JP: Phase II study of gemcitabine (2', 2'-difluorodeoxycytidine) in previously treated ovarian cancer patients. J Natl Cancer Inst 86: 1530-1533, 1994

10. Heinemann V: Gemcitabine: progress in the treatment of pancreatic cancer. Oncology 60: 8-18, 2001.

11. Lee J, Tae N, Lee JJ, Kim T and Lee JH: Eupatolide inhibits lipopolysaccharide-induced COX-2 and iNOS expression in RAW264.7 cells by inducing proteasomal degradation of TRAF6. Eur J Pharmacol 636: 173-180, 2010.

12. Jin HZ, Lee D, Lee JH, et al: New sesquiterpene dimers from Inula britannica inhibit NF-kappaB activation and NO and TNF-alpha production in LPS-stimulated RAW264.7 cells. Planta Med 72: 40-45, 2006.

13. Liu YP, Wen JK, Zheng B, Zhang DQ and Han M: Acetylbritannilactone suppresses lipopolysaccharide-induced vascular smooth muscle cell inflammatory response. Eur J Pharmacol 577: 28-34, 2007.

14. Rafi MM, Bai NS, Chi-Tang-Ho, et al: A sesquiterpenelactone from Inula britannica induces anti-tumor effects dependent on Bcl-2 phosphorylation. Anticancer Res 25: 313-318, 2005.

15. Bai N, Lai CS, He K, et al: Sesquiterpene lactones from Inula britannica and their cytotoxic and apoptotic effects on human cancer cell lines. J Nat Prod 69: 531-535, 2006.

16. Pan MH, Chiou YS, Cheng AC, et al: Involvement of MAPK, $\mathrm{Bcl}-2$ family, cytochrome $\mathrm{c}$, and caspases in induction of apoptosis by $1,6-\mathrm{O}, \mathrm{O}$-diacetylbritannilactone in human leukemia cells. Mol Nutr Food Res 51: 229-238, 2007.

17. Liu S, Liu H, Yan W, et al: Studies on 1-O-acetylbritannilactone and its derivative, (2-O-butyloxime-3-phenyl)-propionyl-1O-acetylbritannilactone ester. Bioorg Med Chem Lett 14: 1101-1104, 2004

18. LiuS,LiuH,YanW,etal:Design,synthesis, andanti-tumoractivity of (2-O-alkyloxime-3-phenyl)-propionyl-1-O-acetylbritannilactone esters. Bioorg Med Chem 15: 2783-2789, 2005.

19. Liu B, Han M, Sun RH, et al: ABL-N-induced apoptosis in human breast cancer cells is partially mediated by c-Jun NH2-terminal kinase activation. Breast Cancer Res 12: R9, 2010.

20. Wang Y, Shi X, Fu Y, et al: Preparation and determination of 1-O-acetylbritannilactone in Inula Britannica L. Se Pu 23: 573-576, 2005 (In Chinese).

21. Baltimore D and Beg AA: DNA-binding proteins. A butterfly flutters by. Nature 373: 287-288, 1995.

22. Gilmore TD, Koedood M, Piffat KA and White DW: Rel/NF-kappaB/IkappaB proteins and cancer. Oncogene 13: 1367-1378, 1996.

23. Boise LH, Gottschalk AR, Quintáns J and Thompson CB: Bcl-2 and Bcl-2-related proteins in apoptosis regulation. Curr Top Microbiol Immunol 200: 107-121, 1995.

24. Korsmeyer SJ, Shutter JR, Veis DJ, Merry DE and Oltvai ZN: Bcl-2/Bax: a rheostat that regulates an anti-oxidant pathway and cell death. Semin Cancer Biol 4: 327-332, 1993.

25. Chao DT and Korsmeyer SJ: BCL-2 family: regulators of cell death. Annu Rev Immunol 16: 395-419, 1998.

26. Fahy BN, Schlieman MG, Mortenson MM, Virudachalam S and Bold RJ: Targeting BCL-2 overexpression in various human malignancies through $\mathrm{NF}-\kappa \mathrm{B}$ inhibition by the proteasome inhibitor bortezomib. Cancer Chemother Pharmacol 56: 46-54, 2005.

27. Rho JK, Choi YJ, Ryoo BY, et al: p53 enhances gefitinib-induced grow th inhibition and apoptosis by regulation of Fas in non-small cell lung cancer. Cancer Res 67: 1163-1169, 2007.

28. Shimizu M, Kondo M, Ito Y, et al: Soluble Fas and Fas ligand provide new information on metastasis and response to chemotherapy in SCLC patients. Cancer Detect Prev 29: 175-180, 2005.

29. Sun SY, Yue P, Hong WK and Lotan R: Induction of Fas expression and augmentation of Fas/Fas ligand-mediated apoptosis by the synthetic retinoid CD437 in human lung cancer cells. Cancer Res 60: 6537-6543, 2000. 